\title{
Structural design optimization of racing motor boat based on nonlinear finite element analysis
}

\author{
Ha Cheol Song*1 ${ }^{1}$ Tae-Jun Kim² ${ }^{2}$ and Chang Doo Jang ${ }^{2}$ \\ ${ }^{I}$ Dept. of Naval Architecture and Marine Eng., Mokpo National University, Mokpo, Korea \\ ${ }^{2}$ Dept. of Naval Architecture and Ocean Eng., Seoul National University, Seoul, Korea
}

\begin{abstract}
Since 1980's, optimum design techniques for ship structural design have been developed to the preliminary design which aims at minimum weight or minimum cost design of mid-ship section based on analytic structural analysis. But the optimum structural design researches about the application for the detail design of local structure based on FEA have been still insufficient. This paper presents optimization technique for the detail design of a racing motor boat. To improve the performance and reduce the damage of a real existing racing boat, direct structural analyses; static and non-linear transient dynamic analyses, were carried out to check the constraints of minimum weight design. As a result, it is shown that the optimum structural design of a racing boat has to be focused on reducing impulse response from pitching motion than static response because the dynamic effect is more dominant. Optimum design algorithm based on nonlinear finite element analysis for a racing motor boat was developed and coded to ANSYS, and its applicability for actual structural design was verifed.
\end{abstract}

KEY WORDS: Optimum design; Finite element analysis; Minimum weight design; Detail design; Transient dynamic analysis; Racing motor boat.

\section{INTRODUCTION}

Optimization techniques for shipbuilding have been developed to design large-scaled commercial vessels based on well-established classification rules and analytical tools, but most of the target model in the past were restricted to the midship section design in the preliminary design stage (Das and Dennis, 1997; Jang and Na, 1996; Shin, Song and Jang, 2006).

On the contrary, design optimization of detail structure based on finite element analysis (Song, Kim and Shim, 2008) has just started recently. But there are few researches about structural design optimization based on nonlinear finite element analysis like transient dynamic analysis.

The minimum weight design of a racing motor boat was carried out to improve the structural strength and reduce the structural response cased by various loading conditions based on static and transient dynamic analysis.

\section{OPTIMIZATION MODEL AND FINITE ELEMENT ANALYSIS}

Target model for structural design was a real-existing

Corresponding author: Ha Cheol Song

e-mail: hcsong@mokpo.ac.kr racing motor boat as shown in Fig. 1. Table 1 and Table 2 show the dimensions and material properties of an actual existing racing boat which used for the finite element analysis during optimization loop.

During the finite element modeling, structural beam element (beam3) was used for the modeling of longitudinal stiffeners, and structural shell element (shell63) for the other parts. Fig. 2 and Fig. 3 describe the characteristics and shape functions of finite elements used in the analysis.

A well-known commercial code, ANSYS, was used as an solver and static and nonlinear dynamic analyses were carried out in this study.

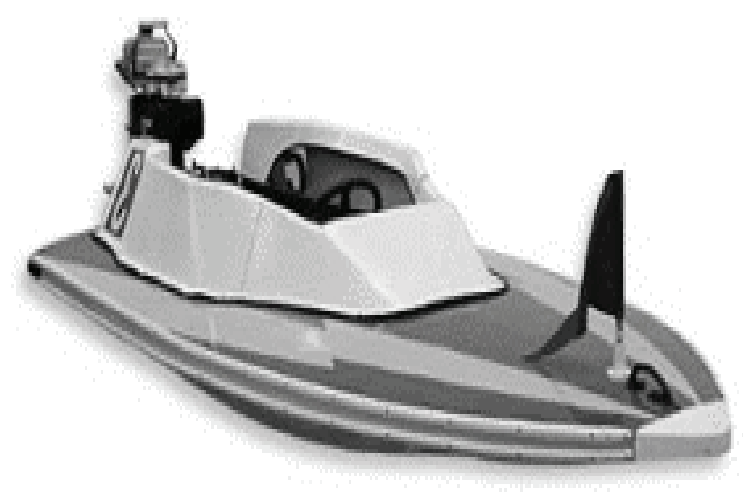

Fig. 1 Optimization model; a racing motor boat. 
Table 1 Structural members and dimensions of racing motor boat.

\begin{tabular}{|c|c|c|c|}
\hline No. & Name & Material & Dimension $(\mathrm{mm})$ \\
\hline 1 & Hull & Birch plywood & 4 \\
\hline 2 & Deck & Birch plywood & 4 \\
\hline 3 & Hull frame & Spruce & 14 (width 40) \\
\hline 4 & Deck frame & Spruce & 14 (width 40) \\
\hline 5 & Side coaming & Birch plywood & 9 \\
\hline 6 & End coaming & Birch plywood & 9 \\
\hline 7 & Coaming stringer & Spruce & $10($ width 60) \\
\hline 8 & Keel & Oak & $50 \times 14$ \\
\hline 9 & Batten-30 & Spruce & $30 \times 18$ \\
\hline 10 & Batten-40 & Spruce & $40 \times 18$ \\
\hline 11 & Batten-20 & Spruce & $20 \times 18$ \\
\hline 12 & Floorboard & Spruce & 10 \\
\hline
\end{tabular}

Table 2 Material properties.

\begin{tabular}{|c|c|c|c|c|}
\hline Material & $\begin{array}{c}\text { Young's } \\
\text { modulus } \\
(G P a)\end{array}$ & $\begin{array}{c}\text { Yield } \\
\text { Stress } \\
(M P a)\end{array}$ & $\begin{array}{c}\text { Poisso's } \\
\text { ratio }\end{array}$ & $\begin{array}{c}\text { Density } \\
\left(\mathrm{kg} / \mathrm{m}^{3}\right)\end{array}$ \\
\hline Spruce & 9.86 & 40 & 0.4 & 450 \\
\hline Birch plywood & 15.00 & 40 & 0.4 & 650 \\
\hline Oak & 10.30 & 40 & 0.4 & 520 \\
\hline
\end{tabular}

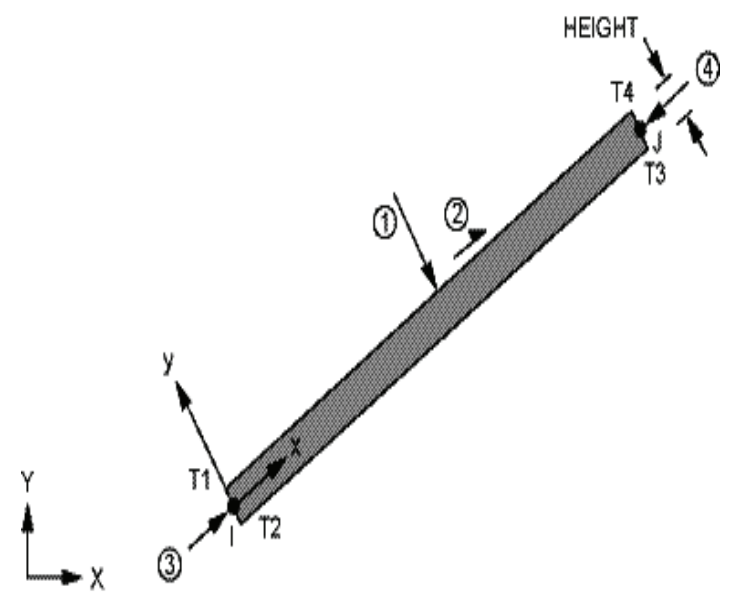

Fig. 2 Description of beam element (beam3).

$$
\begin{aligned}
u= & \frac{1}{2}\left(u_{I}(1-s)+u_{J}(1+s)\right) \\
v= & \frac{1}{2}\left(v_{I}\left(1-\frac{s}{2}\left(3-s^{2}\right)\right)+v_{J}\left(1+\frac{s}{2}\left(3-s^{2}\right)\right)\right) \\
& +\frac{L}{8}\left(\theta_{Z, I}\left(1-s^{2}\right)(1-s)+\theta_{Z, J}\left(1-s^{2}\right)(1+s)\right)
\end{aligned}
$$

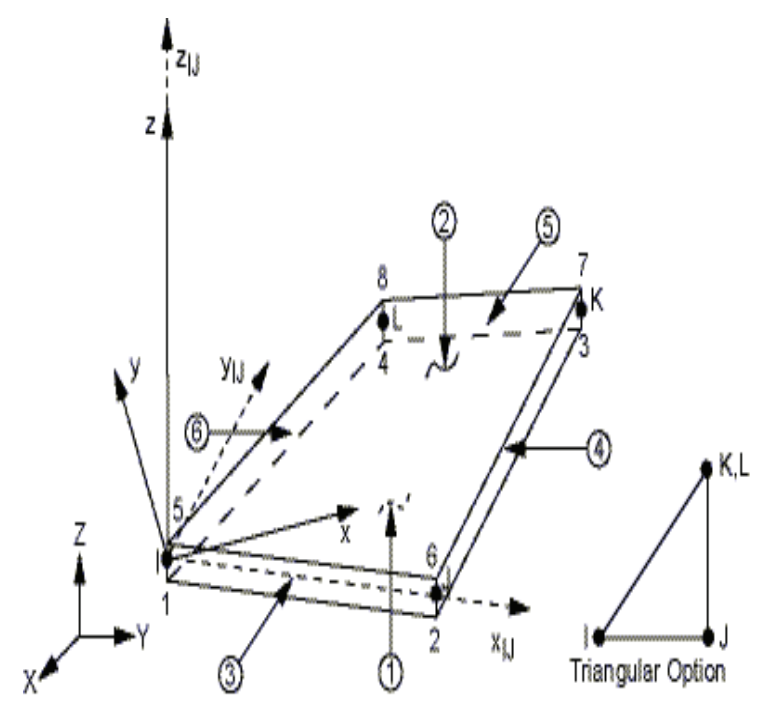

Fig. 3 Description of shell element (shell63).

$u=\frac{1}{4}\left(u_{I}(1-s)(1-t)+u_{J}(1+s)(1-t)+u_{K}(1+s)(1+t)+u_{L}(1-s)(1+t)\right)$

$v=\frac{1}{4}\left(v_{I}(1-s)(1-t)+v_{J}(1+s)(1-t)+v_{K}(1+s)(1+t)+v_{L}(1-s)(1+t)\right)$

\section{STRUCTURAL DESIGN OPTIMIZATION BASED ON STATIC ANALYSIS}

\section{Formulation of Optimization Problem}

Minimum weight was selected as an objective function and von Mises stress (equivalent stress) from FEA was examined as a constraint. Six Design Variables (DV); main dimensions and thickness of stiffeners, frame, deck and hull, were optimized during optimization loop.

Table 3 explains the selected design variables and Fig. 4 shows the structural members and positions of those.

Table 3 Design variables (DV).

\begin{tabular}{|c|c|c|}
\hline No. & DV & Domain of DV $(\mathrm{mm})$ \\
\hline 1 & Location of No.3 frame & $1,980 \sim 2,180$ from origin \\
\hline 2 & Location of No.4 frame & $1,680 \sim 1,880$ from origin \\
\hline 3 & Deck thickness & $2.0 \sim 5.0$ \\
\hline 4 & Side girder thickness & $10.0 \sim 26.0$ \\
\hline 5 & Frame thickness & $6.0 \sim 16.0$ \\
\hline 6 & Hull thickness & $2.0 \sim 5.0$ \\
\hline
\end{tabular}




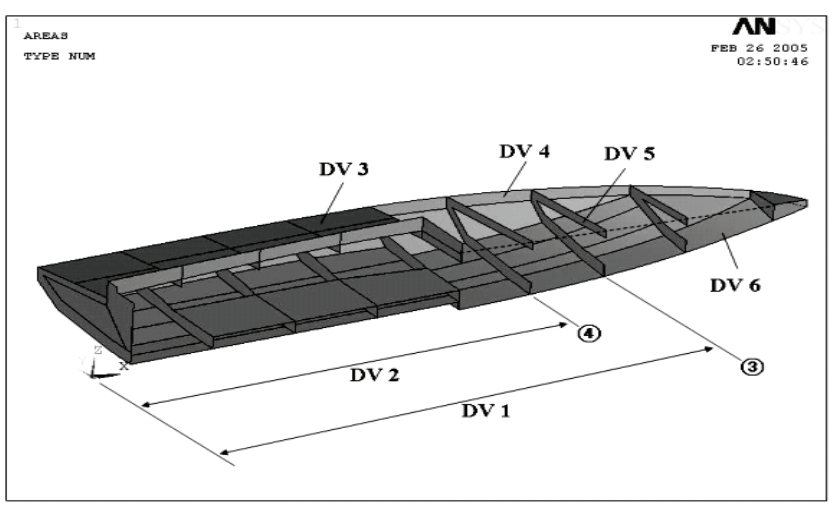

Fig. 4 Design variables for optimization based on elastic analysis.

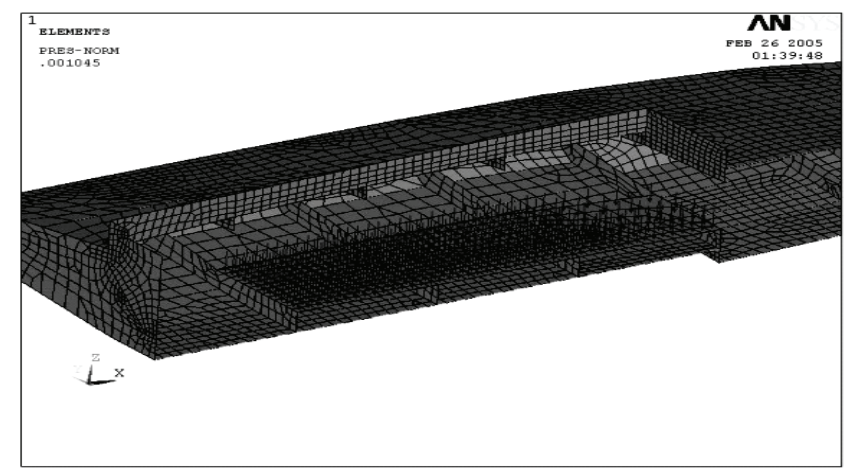

Fig. 5 Applied loading condition.

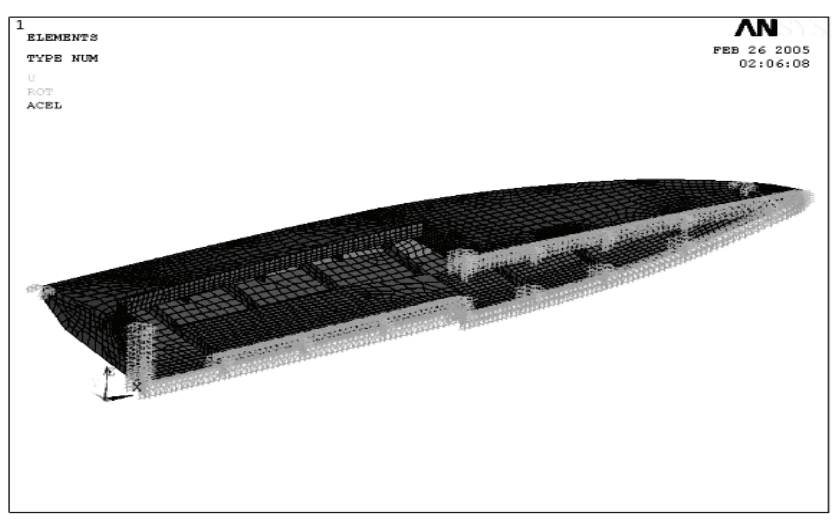

Fig. 6 Applied boundary conditions.

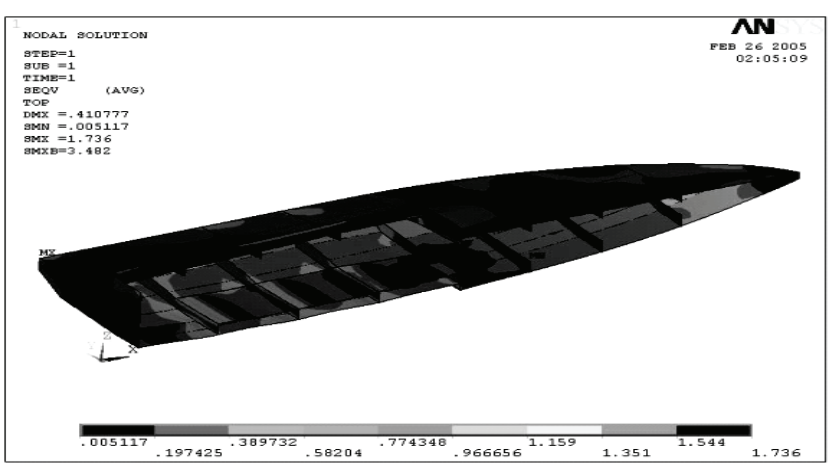

Fig. 7 Von Mises stress distribution.
As a loading condition, distributed load of $60 \mathrm{kgf}$ corresponding to the weight of racer was applied to the floorboard. To maximize the structural response, buoyancy was not considered in static analysis.

Fig. 5 shows the loading condition. Symmetric boundary condition was applied along the centerline of the boat and all the freedoms of at both ends were constrained as shown in Fig. 6.

\section{Results of Structural Analysis and Optimization}

Result of structural analysis according to the abovementioned loading and boundary conditions is shown in Fig. 7. Maximum value of longitudinal bending stress is $1.99 \mathrm{MPa}$ and von Mises stress is $1.74 \mathrm{MPa}$. Maximum displacement occurs at floorboard, approximately $0.4 \mathrm{~mm}$.

During optimization of structural members, $2.0 \mathrm{MPa}$ of von Mises stress adopted as a constraint. As a result of optimization, $19.6 \%$ of the weight compared to the initial design was reduced after optimization loop (Table 4). Sub-problem method supplied by ANSYS (2004) was used as an optimization algorithm and 50 iterations were carried out. Fig. 8 shows the convergence of objective function according to iterations

Table 4 Result of optimization based on elastic analysis.

\begin{tabular}{|c|c|c|}
\hline Items & Initial design & Optimum design \\
\hline Constraint $\mathrm{MPa})$ & 1.74 & 2.00 \\
\hline DV 1 $(\mathrm{mm})$ & $2,080.0$ & $1,987.6$ \\
\hline DV 2 $(\mathrm{mm})$ & $1,780.0$ & $1,879.3$ \\
\hline DV 3 $(\mathrm{mm})$ & 4.0 & 2.1 \\
\hline DV 4 $(\mathrm{mm})$ & 18.0 & 14.8 \\
\hline DV 5 $(\mathrm{mm})$ & 14.0 & 10.1 \\
\hline DV 6 $(\mathrm{mm})$ & 4.0 & 3.1 \\
\hline Total weight $(\mathrm{kg})$ & 36.57 & 29.42 \\
\hline
\end{tabular}

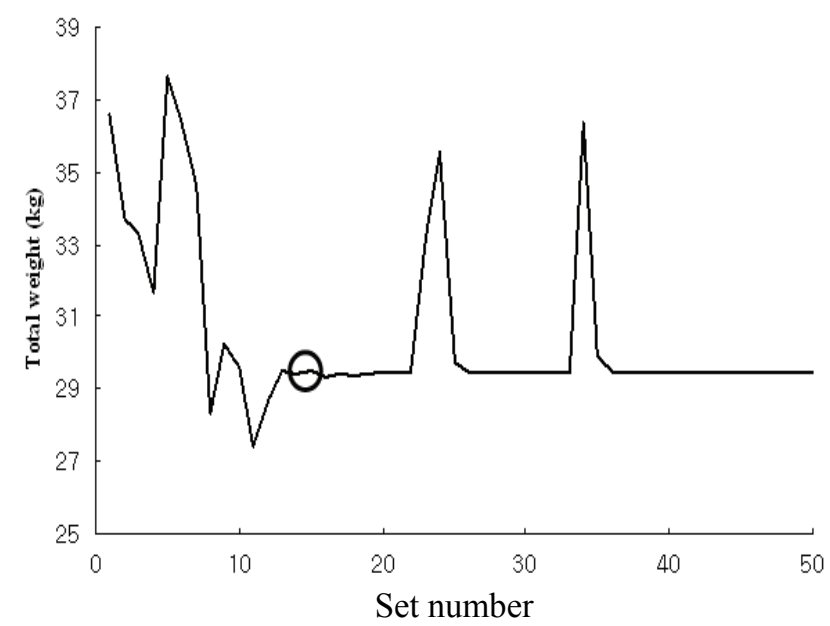

Fig. 8 Convergence of objective function according to iteration. 
Since optimum spacing between No.3 and No.4 frame was so close to each other, some design alternatives could be available for the determination of the number and the spacing of the frames.

Induced stress level of final optimum design was very low compared to yield stress. It can be concluded that optimum structural design considering impulse response is necessary for final design. In case of structural design of racing boat, it is well known that impulse response induced by pitching motion of a boat will be much higher than that of static response.

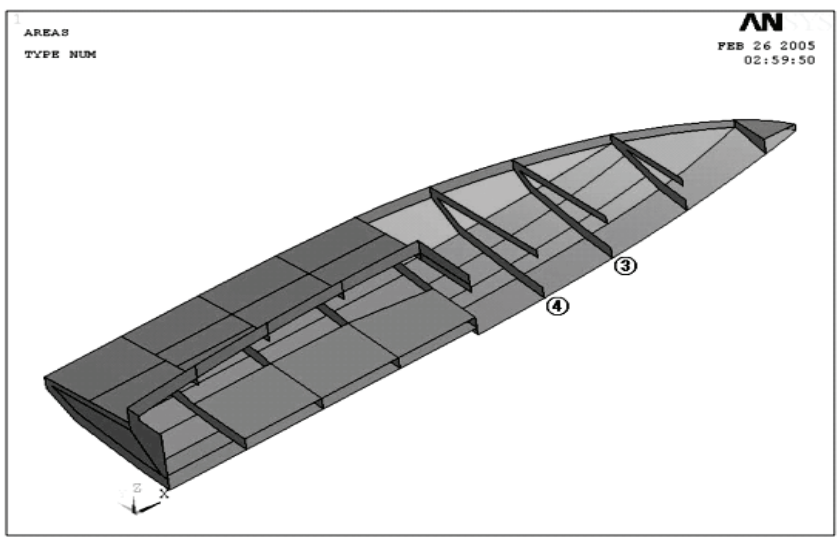

(a) Initial design.

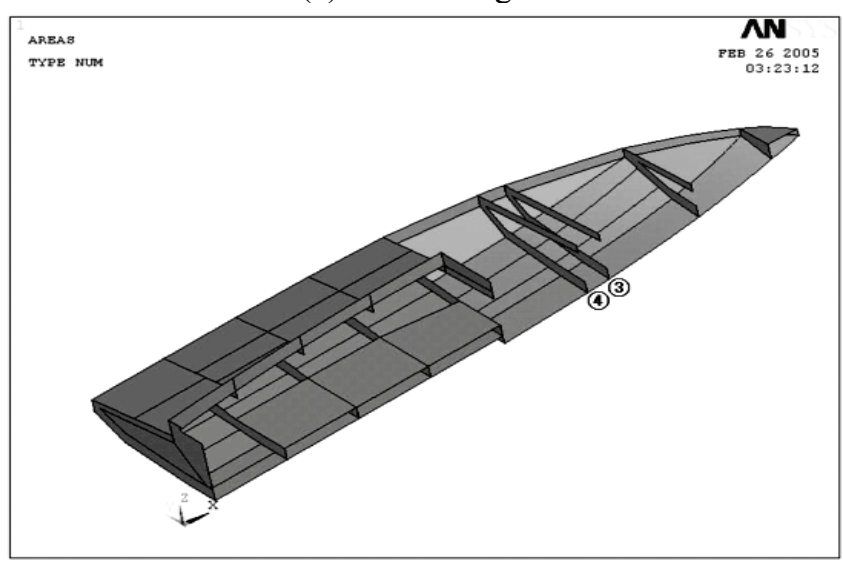

(b) Optimum design.

Fig. 9 Comparison of results due to minimum weight design.

\section{STRUCTURAL DESIGN OPTIMIZATION BASED ON NONLINEAR DYNAMIC ANALYSIS CONSIDERING IMPULSE RESPONSE}

\section{Transient Dynamic Analysis due to Impulse Excitation}

Fig. 10 shows the general forcing caused by contact between bottom of a racing boat and surface of water.

Precise estimation of impulse response is very difficult through experimental or analytic methods. Therefore, we made some assumptions to simulate the impulse load. Duration was assumed as 0.5 seconds, and impulse force $\mathrm{F}_{\mathrm{IMP}}$, the sum of a half weight of motor boat and the weight of racer (Fig. 12).

Dimensions and material properties of boat are same with above-mentioned static analysis model.
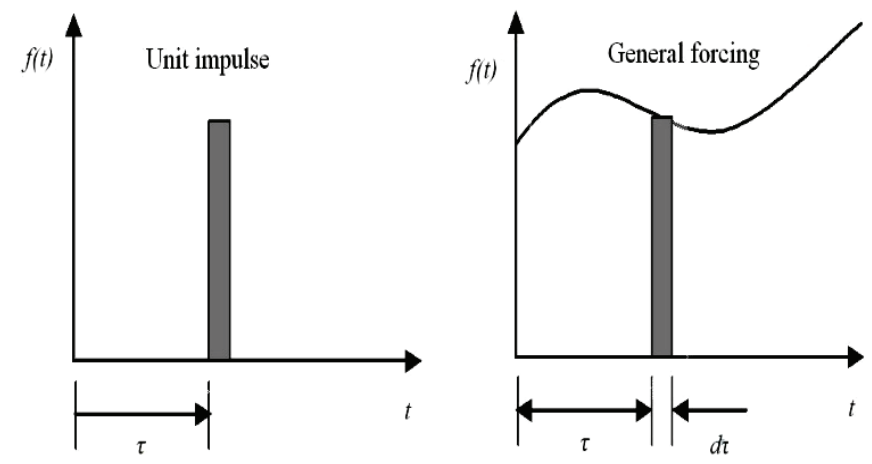

Fig. 10 Description of impulse and general forcing.

$\begin{aligned} u(t) & =0 & & t \leq \tau \\ & =h(t-\tau) & & t>\tau\end{aligned}$

Response due to elemental impulse

$=h(t-\tau) f(\tau) d \tau$

$u(t)=\int_{0}^{t} h(t-\tau) f(\tau) d \tau$
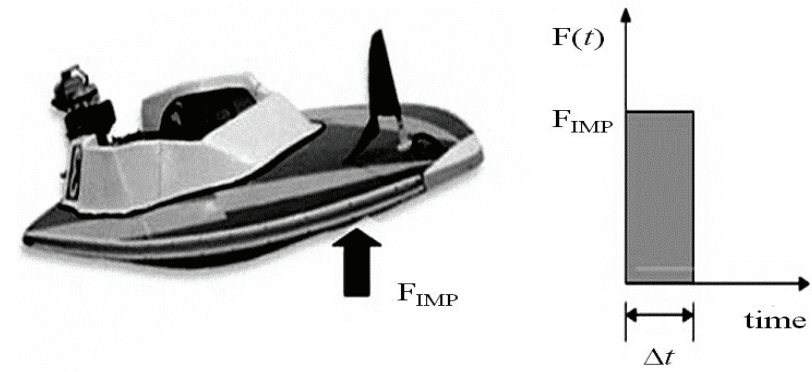

Fig. 11 Modeling of impulse response analysis (transient dynamic analysis).

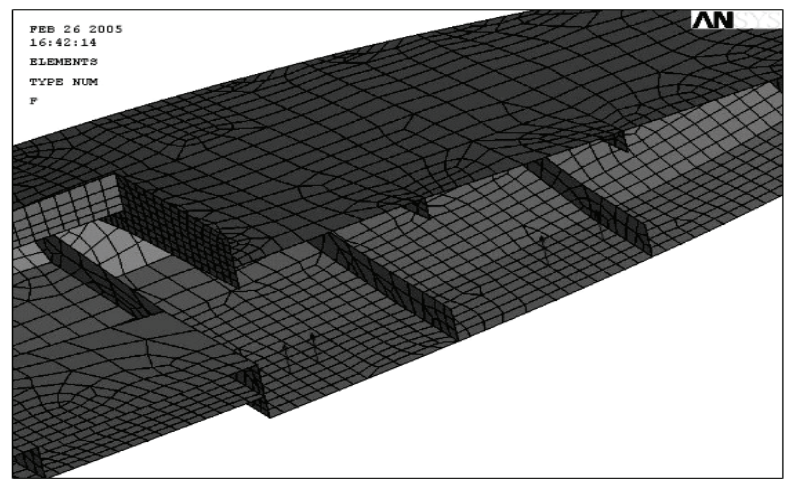

Fig. 12 Applied load to racing motor boat for impulse response analysis. 
Fig. 13 shows that characteristic of impulse transient response of boat when force of $500 \mathrm{~N}$ is applied to boat during 0.5 seconds. Maximum value of von Mises stress is 13.2 $M P a$, and mean stress is $9.01 \mathrm{MPa}$ for 2 seconds. From this result, impulse response has to be considered more important factor than static analysis.

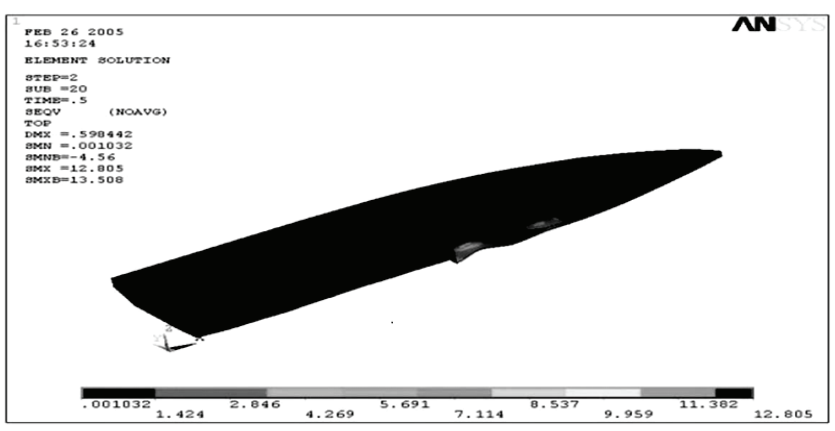

(a) After $0.50 \mathrm{sec}$

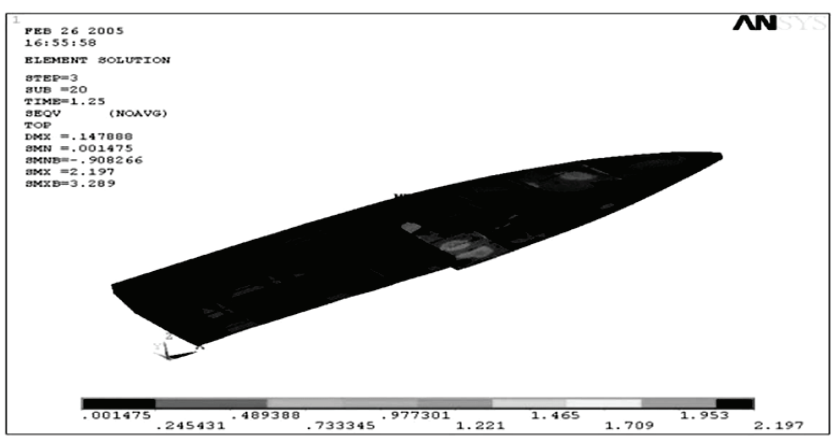

(b) After $1.25 \mathrm{sec}$

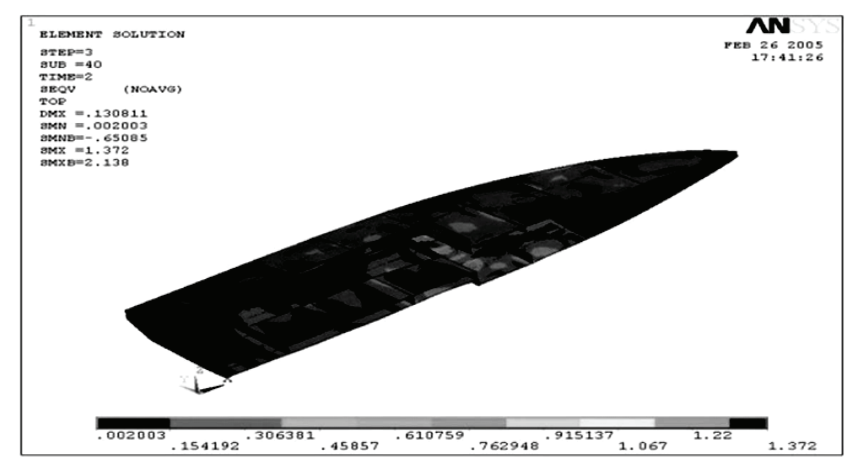

(c) After 2.00sec.

Fig. 13 Impulse response according to time history - von Mises stress.

\section{Result of Optimization based on Transient Dynamic Analysis}

Loading and boundary conditions for optimization based on nonlinear transient analysis were same with preceding analysis. Design constraint was adopted as mean stress not to exceed $7 \mathrm{MPa} ; 22 \%$ less than mean stress from initial design. Object function was minimum weight.
Fig. 14 and Table 5 show specific design variable and domain of design variable. 30cycles of iterations were carried out(Fig. 15).

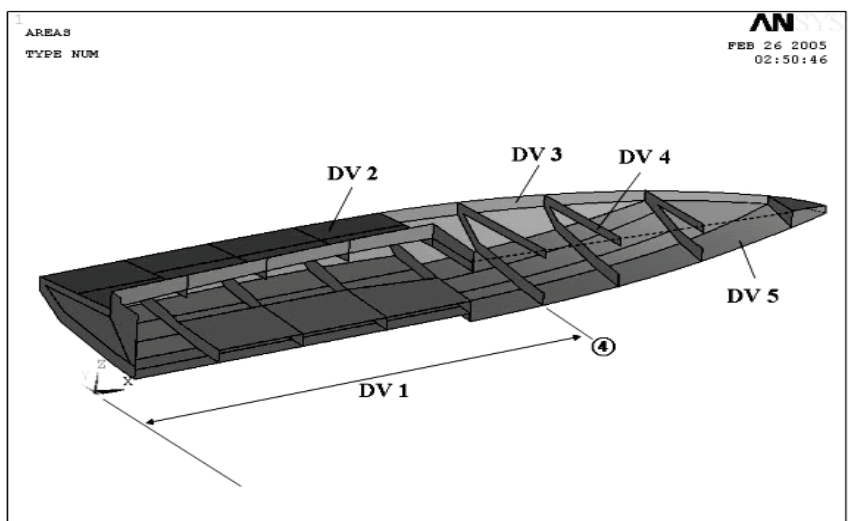

Fig. 14 Design variables for optimization based on impulse response analysis.

Table 5 Design variables (DV).

\begin{tabular}{|c|c|c|}
\hline No. & DV & Domain of DV $(\mathrm{mm})$ \\
\hline 1 & Location of No.4 frame & $1660 \sim 1910$ from origin \\
\hline 2 & Deck thickness & $2.0 \sim 6.0$ \\
\hline 3 & Side girder thickness & $10.0 \sim 26.0$ \\
\hline 4 & Frame thickness & $6.0 \sim 22.0$ \\
\hline 5 & Hull thickness & $2.0 \sim 6.0$ \\
\hline
\end{tabular}

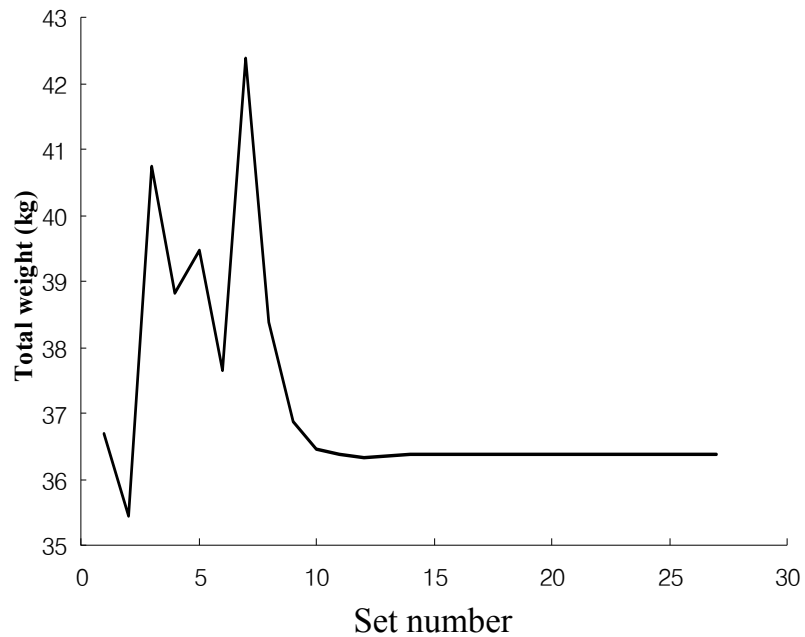

Fig. 15 Convergence of objective function during optimization based on nonlinear transient dynamic analysis.

As an optimization result, mean stress was reduced about $22 \%$ of initial design and the total weight was controlled almost the same with initial design(Table 6).

In case of a racing motor boat, fatigue failure of bottom hull is a main reason of damage. Thus, we can conclude that optimum design considering impact responses is more effective. 
Table 6 Result of optimization based on impulse response analysis.

\begin{tabular}{|c|c|c|}
\hline Items & Initial design & Optimum design \\
\hline Constraint $(\mathrm{MPa})$ & 9.01 & 7.00 \\
\hline DV 1 $(\mathrm{mm})$ & 1780.0 & 1909.5 from origin \\
\hline DV 2 $(\mathrm{mm})$ & 4.0 & 4.5 \\
\hline DV 3 $(\mathrm{mm})$ & 18.0 & 10.0 \\
\hline DV 4 $(\mathrm{mm})$ & 14.0 & 6.0 \\
\hline DV 5 $(\mathrm{mm})$ & 4.0 & 5.0 \\
\hline Total weight $(\mathrm{kg})$ & 36.57 & 36.37 \\
\hline
\end{tabular}

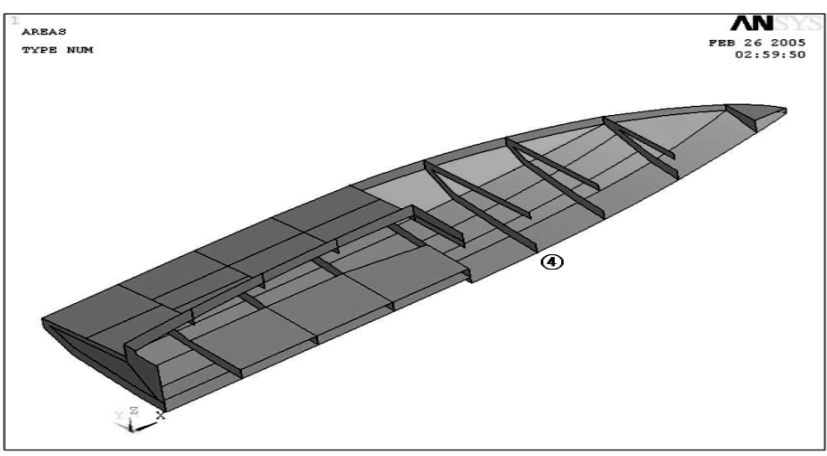

(a) Initial design.

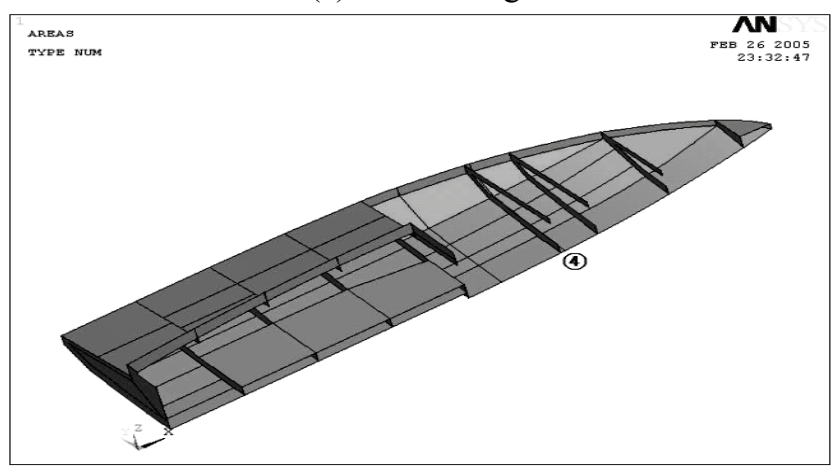

(b) Optimum design.

Fig. 16 Comparison of results due to minimum weight design.

\section{CONCLUSIONS}

Static and non-linear transient dynamic analysis methods of a racing boat were developed for structural design optimization of racing motor boat.

In case of design of high-speed boat suffered by impact loads from pitching motion, impulse response should be considered more important factor than static response.

And it is verified that design optimization based on nonlinear analysis cab be applied to the detail structural design of a real existing racing boat. And it is expected that this study will be used as basic guideline for the optimum design of high-speed vessel.

\section{REFERENCES}

ANSYS, 2004. User's Guide. ANSYS Co.

Das, I. and Dennis, J.E., 1997. A Closer Look at Drawbacks of Minimizing Weighted Sums of Objectives for Pareto Set Generation in Multi-criteria Optimization Problems. Structural Optimization, International Society for Structural and Multidisciplinary Optimization, 14(1), pp. 63-69.

Jang, C.D. and Na, S.S., 1996. Minimum Weight Design of the Transverse Frames of Oil Tankers by Generalized Slope Deflection Method. Journal of the Society of Naval Architects of Korea, 33(3), pp. 103-111.

Shin, S.H. Song, H.C. and Jang, C.D., 2006. Optimum Structural Design of Tankers Using Multi-Objective Optimization Technique, Ships and Offshore Structures, 1(3), pp. 213-219.

Song, H.C. Kim, Y.S. and Shim, C.S., 2008. A Study on the Minimum Weight Design of a Coastal Fishing Boat. Journal of Navigation and Port Research, 32(3), pp. 223228. 